\title{
Forensic Medicine: A source and pathway of recognition in disaster victim identification
}

\author{
Vidhi Soni
}

Forensic Associate, SIFS India, New Delhi

Email: sonividhi811@gmail.com

\begin{abstract}
A mass fatality is commonly construed as a hazardous event resulting in a large number of martyr victims who needs to be identified and subjected to medico legal investigation. During the hazardous consequences of mass fatality incident, it is a necessity to identify the accused sensitively so as to provide judicial assurance and a support to the family members. DVI (Disaster victim identification) team work in an interdisciplinary manner, engaging the services of experts in various disciplines, comprising of forensic medicine, pathologists, anthropologists, odontologists, radiologists, fingerprint and DNA experts to substitute the work in the examination of victims. In accordance to the internationally recognized INTERPOL (International police) DVI guide, the basic quality of standards should be applied and victims must be treated with dignity and respect. This paper focuses on the dynamic applications and significance of forensic medicine which acts as an efficient source of recognition, particularly in the DVI process in setting up a procedure for temporary controlled burial for all the unidentified remains. Different case studies included in this paper reveals the fact that the extensive field of forensic medicine provides a pathway in linking the victims and managing the fatality. Further the reviews relating this field are incorporated in this domain.
\end{abstract}

\section{Introduction}

A disaster is a serious disruption of the functioning of a society, causing widespread human, material, or environmental losses which exceeds the ability of the affected society to cope using its own resources. The term disaster can also be defined as "a catastrophe, mishap, calamity or grave occurrence in any area, arising from natural or man-made causes, or by accident or negligence which results in substantial loss of life or human suffering or damage to, and destruction of, property, or damage to, or degradation of, environment, and is of such a nature or magnitude as to be beyond the coping capacity of the community of the affected area. The country is prone to disasters due to number of factors, both natural and human induced, including adverse topographic features, environmental degradation, population growth, urbanization, industrialization, flawed development practices, etc. Out of 35 States and Union Territories in the country, 27 of them are disaster prone. Almost 58.6 per cent of the landmass is prone to earthquakes of moderate to very high intensity; over 40 million hectares (12 per cent of land) are prone to floods and river erosion; of the $7,516 \mathrm{~km}$ long coastline, close to $5,700 \mathrm{~km}$, is prone to cyclones and tsunamis; 68 per cent of the cultivable area is vulnerable to drought. The studies have shown that incidence of mass disasters is increasing around the world4 and so is the number of victims died and affected. In India alone 59,072 deaths occurred from 1991- 2000 and the number of deaths increased to about 63611 in 2001-2010 due to various disasters.

Some of the historical mass disasters events in India include: when at a school annual function at Mandi Dabwali in Haryana (1995) a tent caught fire killing more than 400 people, including children, 6 the super cyclone in Orissa in October, 1999, 7 the Bhuj earthquake, 2001, 8 Kumbakonam school tragedy 2004, 9 the Kashmir earthquake (also known as the Northern Pakistan earthquake or South Asia earthquake) of 2005, 10 and worst such disasters were at the 2004 Indian Ocean earthquake, known by the scientific community as the Tsunami disaster 10 and the Uttrakhand disaster or the Himalayan Tsunami.

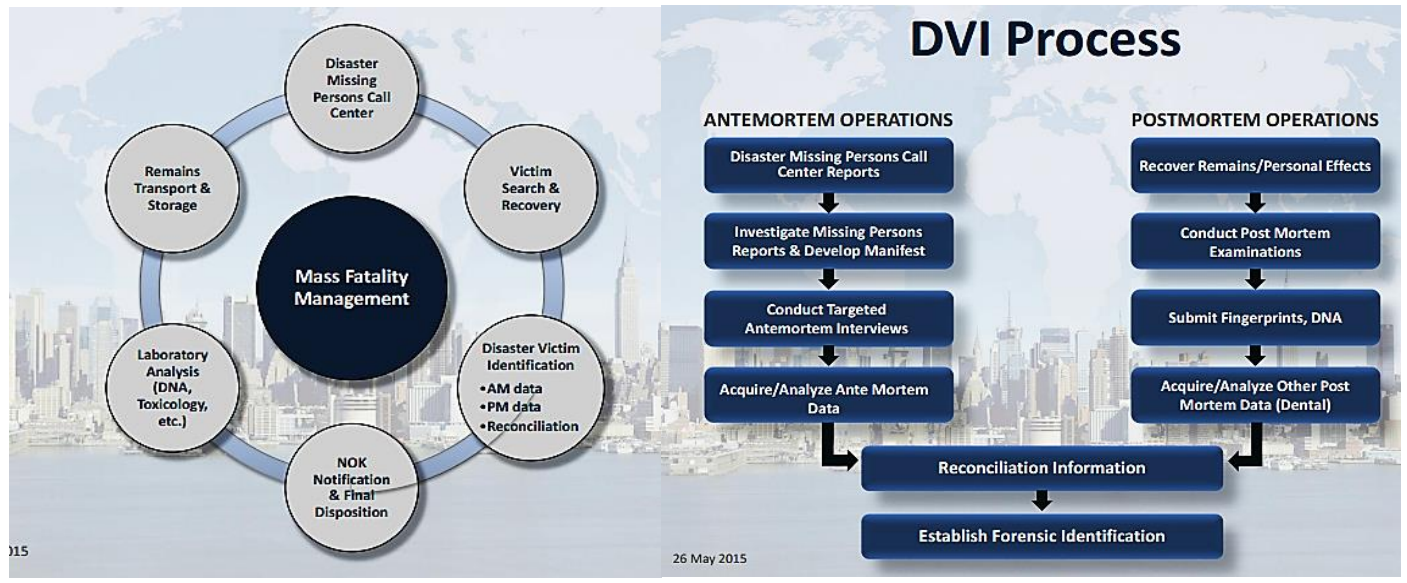

International Journal of Forensic Medicine and Toxicological Sciences, January-June, 2017:2(1):2-7 


\section{Forensic Medicine}

Forensic medicine today is a large medical field that includes many sub areas. However, generally, when one speaks or thinks about it, it is linked with death, autopsies, and related problems. This was only the part of legal medicine, new approaches and sub specialties are realized because of the advances in medical sciences and socio-political changes around the world. The origin of forensic medicine remains lost in a distant past, whenever the principles of medical sciences met those of law and justice. Perhaps it began with the code of Hammurabi (1792-1750 BCE), which imposed sanctions for errors in medical and surgical practices. The same type of punishment also existed in Persia. Later on, the visigoths promulgated laws that punished poisoning, infanticide, and homicide. Described as medical trunk that serves the administration of justice, forensic medicine has different branches. One of the most emblematic one is forensic pathology known in many latin countries as tanathology (thanatos, meaning "death's god"). Many other branches of forensic medicine are emerging with a great significance such as clinical forensics, forensic nursing, forensic anthropology, odontology, osteology, etc. However a substantial loss of human lives can potentially be saved by organizing an efficient and highly co-ordinated system run by professionals who are expert in the field of forensic medicine. There are some obstructions which are being faced due to the lack of trained personnels for initial triage and stabilization, Lack of adequate transport facilities for mass transport, Lack of organized system of levels, lack of capabilities or potential to provide expert opinion, they have led to many serious but preventable socio-economic problems. In fact, in many of these "standard mass disaster plans" the role of forensic medicine expert is being ignored or even, but the fact is that forensic medicine expert has a vital role to play and is indispensable in the case of mass casualty. The ratio of victims vary with the number of disaster and individual characteristics, e.g., cause of injury, pattern of injury sustained, location of victim, etc., Hence these factors underlines the system of disaster mitigation.

Majority of the people are unaware of the importance of preservation and examination of dead and still continues with the age-old casual attitude. Forensic medicine is a coordinated approach of various medical disciplines whose renowned applications may prove to be of great help in determining distinct medico-legal aspects of death in the case of hazardous mass casualty incidents. The significant role of forensic medicine in disaster victim identification process is being described as under:

- Establishing the identity of victims which is the foremost necessity in every disaster so as to detect the identity of the individual and information can be provided to their respected family members.
Most people will find little difficulty to establish the identity from the morphological manisfestation of an intact body.

- In such a case, Forensic pathology can help in establishing the identity from the morphology, anatomy, individual peculiarity, fingerprinting, DNA profiling, etc. There is an importance of establishing the identity because it is common that despite indulging of loved ones in the tragedies, emotionally traumatized family often fails to identify their loved ones due to the disfigurement and mutilitation of bodies, putrefaction, adipocere formation etc.

- Reconstruction of the mutilated remains is the second necessity so as to make the victims representable to the relatives of the deceased. Proper preservation and handling of the remains by the experts may help in preventing the loss of crucial evidences and further putrefaction or adipocere formation and render the situation of health hazards which are mostly common in most of the mass casualties.

- Analysing the cause of disaster by collecting evidence such as: Bomb or detonator fragments embedded in the bodies, toxicological evidences, pathological evidences, biological evidences in case of some impending epidemic or tragedies having biological or chemical sabotage.

- Reconstruction of the cause of the disaster can be achieved by establishing the cause of death, nature and cause of the injuries, position of the remains in relation to the site of the tragedy.

- Determination of the period of survival of victims may be deduced by studying the time since death. It may be helpful in emanating the time of lapse if present during the search and rescue operation. Evaluation of the information during the time of medico-legal investigation can be utilized as a tool for improvising the safety measures.

Hence Forensic medicine as an expert science can be efficiently indulge in the analysis of the victims in the mass casualties and may help in proceeding the disaster management process. Different medico-legal significances of death, injuries included in the branch of forensic medicine helps auspiciously in the mass fatalities.

Considering the massive scale of devastation caused by the calamity it is not surprising that bodies are being found in the area even after a year as the combing operations had to be given up with the onset of winter when the area becomes snow-bound. After disposing 545 bodies in Kedar valley alone in July 2013, 21 more have been found during combing operations this year and it is quite possible that more bodies can be found in days to come as bodies are still trapped under the debris in the area and with the onset of rains they are likely to come to the surface. The 
government of Uttrakhand has already issued the death certificates to 2801 persons. Interestingly, even after a year of the tragedy the death certificates are still not issued to 471 persons. The main reasons cited are improper documentation including First Information Reports (FIR), missing cell data, the affidavits submitted by the claimant relatives of the missing individuals, Improper techniques of identification and the lack of support from other state governments

\section{Case study: Uttarakhand disaster}

Uttrakhand State also called as the "Dev Bhumi' or the "Land of Gods" and is in northern part of India. This state receives large number of pilgrims during the summer months since it is a very important Hindu as well as Sikh pilgrimage. Being a hill state and home to many beautiful hill stations, it also attracts large number of tourists. According to the Indian Meteorological Department, rainfall in Uttarakhand during the week of 17th to 26th June 2013 had been in excess by 37 per cent of normal rainfall. During this period, the state received 73.3 centimeters of rain while the normal rainfall is usually 53.6 centimeters. On 17th June 2013, the Mandakini \& Alaknanda Valley of Garhwal and Saryu \& Kali Ganga valley of Kumaon Himalaya received a heavy downpour and the cloudburst resulted in flash flood which was further intensified by the outburst of Besoka Lake, thus caused a huge devastation. The heavy rains in the region have led to extensive flooding, landslides and destruction to property and lives. The flow in the Mandakini and Alaknanda rivers hit the areas of Sacred Temple of Kedarnath and Badrinath.

Typically, after an incident, the jurisdiction in which the event occurred will conduct and control the identification efforts. However in this case, the outside assistance was very much required as the event exceeded the capacity of local authorities. Soon after the destruction, the NDMA started the Initial Response of Rescue Operation (Operation Rahat \& Surya) by utilizing the Defense and Civil Assets along with NDRF. After the heavy rescue operation the Govt. of Uttrakhand published the list of missing 4,120 (including 92 Foreigners) persons presumed to be dead. Searching the dead bodies is the first step in the management of dead bodies which was mostly chaotic. Communication and coordination between different groups of peoples was required. The phase of body recovery lasted a few days due to difficult terrains, damaged roads and tough weather conditions not favoring the search operations. Usually, the rapid recovery should be the priority as it aids in identification and reduces the psychological burden on survivors. In this case initially the priority was to rescue the survivors by military forces and then search operation for the missing was launched. However recovery of dead bodies should not be interrupted by other interventions aimed at helping survivals. Search work was being done simultaneously by the police personals with the help of mountaineers and locals and the surviving community members. The medical officers were available to look after the injuries, first aid and other medical ailments suffered by the workforce. A number of workers were found to be in need of tetanus vaccination.

\section{Management and identification of the Dead Bodies (Medico-legal aspects)}

Bodies searched were placed together at a cremation site at the end of search. Body parts were treated to be as the individual bodies. Each body was assigned a unique identification number consisting of team number, location number and date of recovery and the articles recovered from each body were placed in separate bags with same UID number and were sealed by the police. Out of About 4, 120 individuals from across the country who have been reported missing and are believed to have died after the tragic flash floods and landslides, Centre for DNA Fingerprinting and Diagnostics (CDFD) has completed DNA profiling of the mortal remains of around 550 victims sent to it by the government of Uttrakhand, and after the preliminary analysis of the results obtained so far identity of only 20 victims could be established. Around 200 blood samples of claimant relatives of the missing individuals had been sent by the government of Uttrakhand which is again a very small fraction of the total required samples for DNA Matching. 

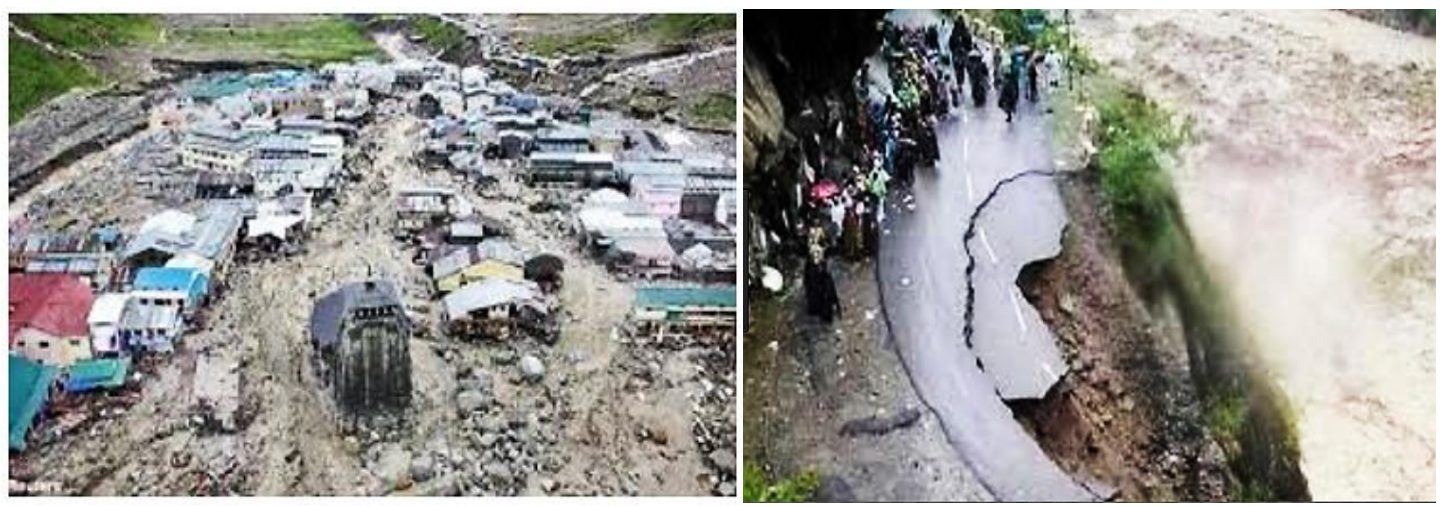

\section{Review of Literature}

Puri et al (2015) demonstrated the aspects of mass disaster with the proceedings of victim recovery and evacuation in which according to the study disaster response planning must include the established procedures for the identification of the victims of the disaster and the identification of victims essentially relies on forensic anthropology, odontology, fingerprints, radiology and DNA typing. This paper aimed at discussing the role of forensic odontology in the Disaster Victim Identification (DVI), its status in India and some suggestions to develop the plans for same.

Winskog et al (2016) discussed the complexities of DVI and variations in situations and numbers of victims as it is difficult to provide a template that can be used for each type of fatality. In this chapter the authors involved a wide range of issues that are needed to be dealt with during DVI exercises, from the initial setting up of mortuaries to the final repatriation of decedents. Lack of on-site resources and the sometime isolated locations provide challenges for the large number of individuals who may be involved, often with different nationalities, languages, religious beliefs and experience. The expanding role of individual disciplines including dentistry, biology, pathology and anthropology is described, as well as the refining and integration of services, the formulation and implementation of international protocols and the overview of processes to ensure that they are fulfilling their role appropriately further they have also covered the evolution of simple victim identification into the complex integrated multidisciplinary approach that is now seen in so many of these events, which should now be more accurately referred to as disaster victim management (DVM).

Obafunwa et al (2015) established the present state of things in the country in terms of legal framework and the availability of personnel with a view to presenting an overview of proper mass disaster investigations. This is a retrospective review of mass disasters in Nigeria that occurred within the last 20 years. The study therefore reviews the state of the forensic investigation of the mass disasters as well as the efforts made to identify the victims of the disaster. The process of proper forensic investigation from the stage of evaluation of the scene and recovery process to the final identification of victims are presented to serve as a protocol for the country. The assessment of the present state of preparedness in Nigeria is also examined with a view to improving the practice to international standards. Data were retrieved from official documents from the aviation industry as well as Nigeria news reports. The standard protocols for disaster victim identification were retrieved from the guide released by the INTERPOL. The state of preparedness of the country and recommendations for improvement are presented. The states of the federation should without further delay put in place the process of reviewing the law of Coroner's system and provide the enabling environment for the proper forensic investigation. The training curriculum of the first responders should incorporate mass disaster investigations in order to produce efficient officers and personnel. A functional disaster victim identification (DVI) team is strongly advocated to incorporate different professionals involved in mass disaster management.

See et al (2016) shared his views in the context of mass fatality incident, it is of utmost importance to identify the victims rapidly and accurately, both for judicial reasons and to provide closure for family members. DVI teams work in an interdisciplinary manner, engaging the services of experts in various disciplines, comprising of pathologists, anthropologists, odontologists, radiologists, fingerprint and DNA experts to work collaboratively towards the identification of victims. The DVI process is conducted by adopting the fundamental principle where the highest possible quality standards should be applied and victims are to be treated with dignity and respect, in accordance to the internationally recognized INTERPOL DVI guide. This paper focuses on the dynamic and continuous evolution, particularly the application of the DVI process in setting up a procedure for temporary controlled burial for all the unidentified remains in the two cases of Malaysia mass fatality. The two cases discussed conveys the importance of 
expanding the DVI process to include procedures for future identification and archiving. This extended version of the DVI protocol can be used for temporary controlled burial for all the unidentified remains as means of forensic humanitarian reason as well as for criminal investigation.

Lessig et al (2011) incorporated his study under the specialists of the Department of Legal Medicine of the "Sapienza" University of Rome (Italy) which were involved in the investigation of ten mass disasters over fifty years (1964-2005). The victims examined were 230. The cases, distributed both in Italy and abroad, included four terrorist attacks, three airplane accidents, two collapsed buildings, and one shipwreck in a river. One of the most important tasks in mass disasters is the identification of victims. Another key issue is the determination of the cause of death and the contribution to the reconstruction of the events. In all cases the training and the capability of our specialists to interact with all the entities involved in the mass disaster management played a critical role. For all cases the timeline of operations was provided, beginning with the collection of the antemortem information. Specialists of our Department took part to the antemortem teams, due to their particular experience. For postmortem collection of information our Institute historically played a central role, especially because all the Italian victims of any accidents happened abroad were examined in "Sapienza" smorgue. The aim of this contribution is to highlight the changes that have occurred over the years in the management of mass disaster investigations in Rome and to present the latest developed organisation of specialists involved.

Binz (2007) discussed the proper management of the dead from catastrophes, together with the rescue and care of survivors and the provision and rehabilitation of essential services. In 2006 the Pan American Health Organisation (PAHO) and the International Committee of the Red Cross (ICRC), together with the World Health Organisation (WHO) and the International Federation of Red Cross and Red Crescent Societies (IFRC), published guideline for the management of the dead, to help improve the management of the dead after catastrophes. This publication helped to dispel the principal myth which often complicates this difficult task: the unfounded association of cadavers with epidemics. The manual has proven to be a valuable tool for first responders, including humanitarian workers, for disaster response and preparedness in various operational contexts.

Jain et al (2006) dealt with definition and meaning of mass disaster, need for management plan for forensic Medicine expert so that Medical officers and Forensic expert can efficiently work during mass disaster. There are certain fundamental principles which should be thoroughly understood by everyone who may have responsibility for helping the victim of a disaster, it is important that these principles be applied in the proper sequence; otherwise they loose effectiveness or cause even more deaths and injuries.

Sharma et al (2006) discussed the concept of minimal acceptable care is the key to a staged management approach during a mass-casualty incident. However, any plan without provision for the dead during a mass casualty incident will obviously be found lacking, leaving a massive and unprepared crisis. During a multiple-casualty incident, a large casualty caseload adversely affects the quality of trauma care given to individual patients. From a trauma care perspective, the goal of the hospital emergency plan is to provide severely injured patients with a level of care that approximates the care given to similar patients under normal conditions. Therefore, the realistic admitting capacity of the hospital is determined primarily by the number of trauma teams that the hospital can deploy. Effective triage of these casualties is often not straightforward, with high over triage rates. Simplified triage algorithms may be a practical alternative to more elaborate schemes.

Lessig et al (2006) evaluated the case study of tsunami after the sea quake in Southeast Asia at the 26th of December 2004 which represents one of the largest disasters in the modern World. Approximately 228,000 people from the countries surrounding the Indian Ocean have died. A large number of visitors from different European countries staying for their Christmas holidays in Thailand and Sri Lanka became victims of the natural disaster. The large number of foreign victims in these countries required additional forensic investigations which were organized by internationally working DVI (Disaster Victim Identification) teams. Victim identification was a great challenge due to the environmental conditions rapidly leading to heavily decomposed bodies. Thus the forensic medical investigations were very important to identify the victims. The different steps of forensic medical, odonto-stomatological and molecular genetic investigations beginning at the end of 2004 with the identification of a small number of victims and ending with the closing of the TTVI IMC (Thai Tsunami Victim Identification Information Management Center) in Phuket one year later are described and critically discussed. Up to 31 international DVI Teams worked in the TTVI IMC during 2005.

Taylor (2009) summarized some of early uses of forensic odontology internationally and in austrailia and discussed the development of both forensic odontology and disaster victim identification practices in each of the states and territories of austrailia. The development of DVI practices in austrailia began following the crash of a Vickers viscount aircraft into botany bay in 1961 and as with practices internationally, have evolved into an equally professional and a reliable specialist discipline of policing in which forensic odontology plays a significant part. 
Ishwer et al (2014) aimed on the aspects of the preparedness, readiness and the role of Indian forensic professionals towards the Disaster Victim Identification. The present case study is about the flash flood disaster due to sudden cloud burst in Uttrakhand, India 2013, the deployment of Forensic Experts at ground zero and their work regarding searching and management of dead victims to aid their identification.

\section{Discussion and Conclusion}

This present study aimed at the scope of identification with the effective science of forensics i.e., Forensic medicine, further this study helped in reviewing the present situations and criteria's of the management process in different mass fatalities. These mass casualties flash away the life of millions of people who have to suffer in an inadequate manner. This study also focused on the views and suggestions to improve the techniques of forensic medicine and replenish and fasten the process of DVI under the expert supervision. This particular study is being discussed with the paper prepared by sharma et al who have discussed the role of forensic medicine in the mass casualty incident whereas above review article presented the scope and the significance of forensic medicine in the disaster management process which may help in improvising the extensified science of forensic medicine and can support in revealing better results in the analysis. The hurdles caused during the medico-legal examination of the mutilated bodies are also being dicussed. Further the review also includes a case study on uttarakhand disaster which initiated in generating an example of the type of obstructions coming in the path of identification procedure and evaluated different concepts of medicolegal importance of this field.

Sharma et al (2006) discussed the concept of minimal acceptable care is the key to a staged management approach during a mass-casualty incident. However, any plan without provision for the dead during a mass casualty incident will obviously be found lacking, leaving a massive and unprepared crisis. During a multiple-casualty incident, a large casualty caseload adversely affects the quality of trauma care given to individual patients. From a trauma care perspective, the goal of the hospital emergency plan is to provide severely injured patients with a level of care that approximates the care given to similar patients under normal conditions. Therefore, the realistic admitting capacity of the hospital is determined primarily by the number of trauma teams that the hospital can deploy. Effective triage of these casualties is often not straightforward, with high over triage rates. Simplified triage algorithms may be a practical alternative to more elaborate schemes.

Soni (2017) explained that mass fatality is commonly construed as a hazardous event resulting in a large number of martyr victims who are needed to be identified and subjected to medico legal investigation.
Due to the hazardous consequences of mass fatality incident, it is a necessity to identify the accused sensitively so as to provide judicial assurance and a support to the family members. DVI teams work in an interdisciplinary manner, engaging the services of experts in various disciplines, comprising of forensic medicine, pathologists, anthropologists, odontologists, radiologists, fingerprint and DNA experts to substitute the work in the examination of victims. In accordance to the internationally recognized INTERPOL DVI guide, the basic quality of standards should be applied and victims must be treated with dignity and respect. This paper focuses on the dynamic applications and significance of forensic medicine which acts as an efficient source of recognition, particularly in the DVI process in setting up a procedure for temporary controlled burial for all the unidentified remains. Different case studies included in this study reveals the fact that the extensified field of forensic medicine provides a pathway in linking the victims and managing the fatality. Further the reviews relating this field are incorporated in this domain.

\section{References}

1. Binz M.T., "Managing the dead in catastrophes: guiding principles and practical recommendations for first responders", International review of the red cross (2007), Vol 89 No.866.

2. Jain R., Rajoo K.M., "Mass disaster management: forensic aspect", J Indian Acad Forensic Med (2006), 31(2).

3. Sharma B.R., Singh H., "Role of forensic medicine in mass casualty incident", JPAFMAT (2006);6.

4. Lessig R, Grundmann C, Dahlmann F, Rötzscher K, Edelmann J, Schneider P.M., "Tsunami 2004 - A review of one year of continuous forensic medical work for victim identification", EXCLI Journal 2006.

5. Prieto J. L., Tortosa C., Bedate A., Segura L., Abenza J.M., Mariscal de Gante M.C., Conejero J., Magaña C., Perea B., "The 11 March 2004 Madrid terrorist attacks: the importance of the mortuary organisation for identification of victims-a critical review", Int J Legal Med (2007) 121:517-522.

6. Taylor J., "A brief history of forensic odontology and disaster victim identification practices in Australia", J Forensic Odontostomatol (2009) 64-74.

7. Lessig R.D., Rothschild M., "International standards in cases of mass disaster victim identification (DVI)", Pubmed Forensic Sci Med Pathol (2011).

8. Winskog C., Byard R.W., "Evolution of disaster victim identification (DVI/DVM): An overview of management and pitfalls", Springer (2016) pp 515-533.

9. Obafunwa J.O., Faduyile F.A., Soyemi S.S., Eze U.O., Nwana E.J., Odesanmi W.O., "Forensic investigation of mass disasters in nigeria- a review", Pubmed(2015) Vol 56 Issue $1 \mathrm{Pg} \mathrm{1-5.}$

10. See K.L., Aziz S., Mahmood M.S., "Beyond DVI: Future identification, research and archiving", Forensic Science Criminology (2016) Vol 1(1).

11. Ishwer T., Malik P.P., Mohammad I., Maneel G., Chandra P., "Uttrakhand Disaster: Status of disaster victim identification in India", Austin J Forensic Sci Criminol. 2014; 1(1).

12. Puri M.P., Khajuria H., "Disaster Victim Identification (DVI) through dental evidence: overview and challenges in Indian scenario", IJRSI (2015), Vol II, Issue II, February 2015. 